\title{
Ubuntu as care: Deconstructing the gendered Ubuntu
}

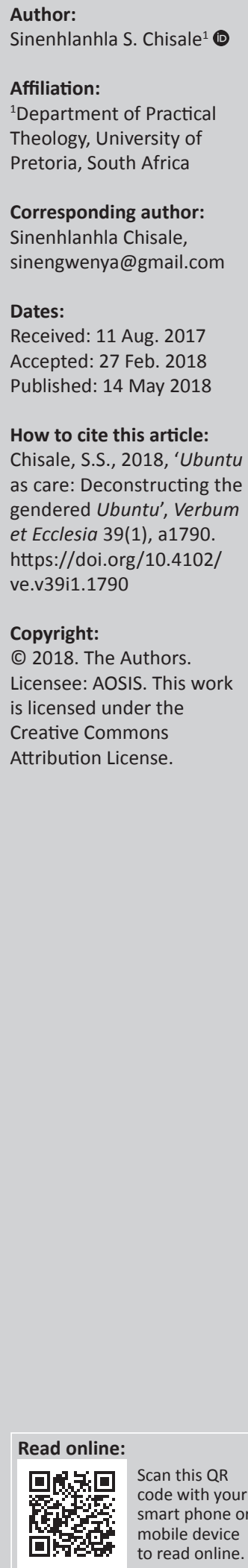

In this article, I explore the concept of Ubuntu in a context of caregiving with the aim of deconstructing the gendering of caregiving in a context of pastoral care. Using a qualitative approach, this article draws from the empirical findings of primeval praxis of Ubuntu from a study conducted on the KwaZulu-Natal chapter of South Africa's National Research Foundation (NRF) funded 'Archaeology of Ubuntu' project. Empirical findings were evaluated through African women theology. Findings of this article highlight that Ubuntu in a context of caregiving is not exclusively feminine because men also display strong tendencies of care in African traditional communities. This suggests that pastoral care in an African context should not be gendered because findings of the article confirm that the Zulu elders from KwaZuluNatal generally linked Ubuntu to communal care where men and women partnered in extending caregiving to those in need.

Intradisciplinary and/or interdisciplinary implications: Although the article is written from a socio-anthropological perspective, it integrates African traditional presumptions of gender and care ethics that are significant in extending pastoral care by reviewing literature from sociology, anthropology, gender, feminist studies, practical theology and systematic theology.

\section{Introduction}

Ubuntu has become synonymous with care ethics. The main purpose of this article is to explore how the elderly members of the community from Kwa-Zulu Natal (KZN) Province conceptualised the philosophy of Ubuntu in a context of caregiving. The significance of engaging community elders in addressing the issue of Ubuntu in a context of caregiving is that they are 'regarded as the custodians of indigenous knowledge' (Keane 2017; Letseka \& Letseka 2017). In South Africa, reference is always made to Ubuntu for communities living in harmony and interdependence (Letseka 2012). Although there is no homogeneity in Africa, the Ubuntu philosophy suggests some form of a homogeneous culture in southern Africa. Caregiving is a characteristic and a regular normative of Ubuntu (Metz 2007), that is, at times misinterpreted to be gendered. Published research on Ubuntu (Hall, Du Toit \& Louw 2013; Letseka 2012; Mangena 2009) highlights the gendered stereotyping of Ubuntu. Those who research on Ubuntu and gender seem to be attributing Ubuntu to a philosophy that enforces patriarchy in African communities (Du Toit 2011; Mangena 2009; Manyonganise 2015). On the contrary, some research highlight Ubuntu as a double-edged sword that empowers women on the one hand by advocating for notions of equality and human dignity and, on the other hand, oppresses them by perpetuating the masculine authority and patriarchal values (Chirongoma, Manda \& Myeni 2008; Chisale 2016a; NgubaneMokiwa 2016). The liberative potential of Ubuntu to women is ambiguous because of the fluidity nature of the philosophy. Thus, the gender fairness nature of the Ubuntu philosophy is not clear because gender research highlights mainly its patriarchal values. Ubuntu in a context of caregiving is alleged to be feminine (Chirongoma et al. 2008; Mangena 2009; Manyonganise 2015). The gender inclusiveness of Ubuntu in caregiving is concealed, where care is assumed to be an ethic that is visible from women rather than men. Held (2005) defines care as a practice and a value that is extended by caring persons who are not only motivated to care and participate in effective practices of care but are compelled by moral salience of attending to and meeting the needs of the particular others for whom they take responsibility.

\section{Problem statement}

In African contexts, social communal unpaid care is assumed to be feminine. This becomes complicated in contexts of pastoral care. Social communal unpaid caregiving such as mothering, care for children, elderly, and people with disabilities, visitors and extended family is primarily considered as feminine vocations by society and theorists of care such as Gilligan (1982) and 
Noddings (1995). Gilligan's findings suggest that women embody the characteristic of care and well-being (Gilligan 1982; Noddings 1995). According to Gilligan, care focuses on relationships, context, responsiveness, compromise and accommodation (1982) that is primarily extended by women. She asserts that care has to do with attentiveness to others, trust, responsiveness and responsibility and personal relationships that are mainly the focus of women. In agreement, Rachels and Rachels (2012:150-152) argue that women are far more empathetic and caring about close personal relationships because of the social roles they were socialised to fulfil through psychological conditioning, whereas men generally seem to have been socialised to care about shallow relationships (Nicolaides 2015). Such conceptualisation of care encourages some people to resist pastoral caregiving initiatives by males because of the assumption that it is a transgression to normal life. In contexts of pastoral care, there are complexities and contestations, if caregiving is feminine, because those presumed to be pastoral caregivers are the ordained ministers who are unquestionably dominated by the male clergy. Does this then place pastoral care in a crisis? As much as it is uncontested truth that women provide deep and larger amounts of caregiving compared to men, the aim of this article is to advocate for the acknowledgement that in pastoral care, both men and women, clergy and lay people should work as partners in extending pastoral caregiving, following the elderly's narratives about Ubuntu in a context of caregiving.

Although literature has addressed the gender connotations of Ubuntu in a context of caregiving, in my view, it is primarily conceptually controversial and speculative. My article contributes a different view, in that it draws from empirical data. The aim of the article is to present how the elderly from the Greater KwaZulu-Natal conceptualise Ubuntu in a context of caregiving and the implications of this to pastoral caregiving in an African context. This article is therefore divided into five sections; first section is a discussion on the methodology used in the article. Second section is a discussion on the chosen theoretical perspective of the article. Third section is a presentation on Ubuntu as a principle of pastoral care. In the fourth section, drawing from African women theology's perspective of pastoral care and themes that emerge from participants on their understanding of Ubuntu in a context of caregiving are presented. The last section is a discussion of emergent themes and their implications to pastoral caregiving in the African contexts.

\section{Methodological considerations}

Drawing from the greater KwaZulu-Natal chapter of the NRF funded 'Archaeology of Ubuntu' study, the focus of this article was to explore how elderly community members above the age of 65 conceptualised Ubuntu in a context of caregiving. Data for this article are drawn from a qualitative study that involved oral historical conversations (structured interviews) with the elderly from KZN communities. An oral history methodology is a technique where the recorded memories of a research participant who has first-hand knowledge of past experiences takes precedence (Janesick 2007). Vansina (1985), a historian, articulates that oral history traditions are documents of the present that tell the story of the past. According to Vansina (1985:12), 'the sources of oral history are reminiscences, hearsay, eyewitness accounts about events and situations which are contemporary, that is which occurred during the lifetime of the informants'. In cognisance, oral history can reveal how people's values and actions shaped the past and how the past shapes the presentday values and actions (Sommer \& Quinlan 2009). Gender and feminist researchers favour this method of research because it allows and accepts individual subjectivity and experiences in empirical data. Thus, although there is room for objectivity in research about caregiving, the search for a deeper understanding of intimate perceptions and experiences of caregiving allows me to focus on the subjective experiences of the elderly above the age of 65 . In my view, their age qualifies them to have knowledge and experiences of the phenomenon under investigation. The significance of oral history research is that it allows the voices of those who have been ignored, marginalised and silenced within particular contexts to be heard (Sommer \& Quinlan 2009).

Empirical research for the 'Archaeology of Ubuntu' study was conducted during the months of February and March 2015. The data were collected from oral historical conversations from structured and focus group interviews with 20 elderly men and 30 elderly women from greater KZN whom informed consents for participating in the interviews and focus groups were signed. The youngest participant was aged 67 and the eldest 96. Participants were recruited through purposive sampling. Purposive sampling takes place on the basis of the researcher's knowledge of the population, its elements and the nature of the research objectives (Babbie \& Mouton 2011). According to Terre Blanche, Durrheim and Painter (2006), this sampling technique is influenced by the subjective considerations of the researcher than by the scientific criteria. For the purpose of the 'Archaeology of Ubuntu' project, all elders who volunteered to participate were included in the sample.

All participants were briefed on the ethical principles governing research with humans such as informed consent, voluntary participation and withdrawal at any stage without consequences, confidentiality and identity protection of research participants. This study ensures the identity protection of all participants by using pseudonyms to refer to participants. Empirical data were audio recorded to capture how African community elders responded to various acts of morality and moral indiscretion (Chisale 2016a). Empirical data were collected in Zulu and translated to English by an African linguist. The use of the elderly's vernacular language gave this study what Letseka and Letseka (2017) call 'indigenous African epistemology'. Data were then analysed through thematic analysis to isolate major trends and subthemes emerging from respondents about Ubuntu in a context of caregiving. In thematic analysis, themes are identified and interpreted through analysing and reporting patterns within data (Braun \& Clarke 2006). 


\section{An African woman theology's perspective of pastoral care}

African women theology begins with women doing theology from their cultural and religious experiences. For the purpose of this article, I use African women's theological approach to explore how the elderly members of the community from KwaZulu-Natal province conceptualised the philosophy of Ubuntu in a context of caregiving. African women theology challenge everybody to use gender lenses in the reading of sacred scriptures and culture in order to promote equality among women and men in different sectors of society (Phiri 1997:69). Caregiving is presumed to be feminine by culture and religion. African women theology demands that any sexist oppression should not be granted any truth and authority in today's world (Wangila 2007:34). If caregiving is presumed to be feminine, pastoral care is also practically presumed to be feminine. The traditional functions of pastoral care are healing, sustaining, guiding, reconciling, nurturing, liberating and empowering (Lartey 2003:60-68). Generally, these functions are presumed feminine by culture and they summarise the philosophy of Ubuntu. Pastoral care in a Christian context is supposedly a clergy's vocation; the church is dominated by male clergy who sometimes struggle to extend some pastoral care functions to communities and congregants because of the assumption that they are feminine. In such cases, prayer women's league (PWL) end up taking some responsibilities of pastoral care to facilitate the wellbeing of congregants and communities' souls. Pastoral care involves concern and action by a particular person or community. In a Christian context, pastoral care is often conceptualised as '... helping acts done by representative Christian persons ...' (Clebsch \& Jaeckle 1964:4). In an African context, pastoral care is a communal responsibility extended by concerned community members or churches. Community is a critical theme in African women's theology. According to Kasomo and Masemo (2011:158), the well-being of a community is understood as a responsibility of women who are assigned to take care of the extended family and the whole community.

Significantly, African women theologians identify positive aspects of culture and promote them (Kasomo \& Masemo 2011:159-161) for the well-being of the community. African women, like, other than African feminists, resist western hegemony and its legacy within African culture (Mikell 1997:4) for creating gendered communities. For African women theologians, men are not enemies, rather the patriarchal system that elevates men over women is the problem (Dube 2007:364). According to Kanyoro (2001:106107) '... Some African women reason that they want a future in which men are friends'. Building that future does not begin by attacking men but by finding methods of bringing change together with them. 'This is a tall order, but it is the reality of the lived experience of African women.' 'The communal principle is the core of African relations' (Kasomo \& Maseno 2011:154-155). The gendering of men and women is rejected and problematised as an injustice to the community. This suggests that men and women deserve the same treatment both in society and church. Thus, African women's theology is relevant in understanding how traditional African communities like elderly men and women from KZN conceptualise Ubuntu in a context of caregiving. This is significant because community elders are the custodians of indigenous knowledge, the death of an elderly person is the loss of a significant source of indigenous knowledge. Jewsiewicki and Mudimbe (1993:3) rightly argue that 'every time one of the elders dies, a library disappears'. Pastoral care is not a new phenomenon; it existed in African history; as a result, the elderly are the significant and authentic sources of how caregiving is ought to be.

\section{Ubuntu as a Principle of pastoral care: A conceptual analysis}

I understand Ubuntu as an African philosophy that is unique and is embedded in moral values of African communities. Letseka (2012:48) conceptualises Ubuntu as 'humanness, personhood and morality'. Ubuntu allows communities to live in right relationships with each other, God, ancestors, self and the universe. Ubuntu promotes morality. Letseka (2013a:351) argues that 'young people who are initiated into Ubuntu morality have the potential to become citizens that are inclined to treating others with justice and fairness at all times'. The philosophical interpretations of the values of Ubuntu are embedded in pastoral care ethics that encourage the treatment of one another with dignity and fairness.

The interdependence of human beings on each other and other creation conceptualise Ubuntu as communal. This means that Ubuntu is similar to an 'unbroken circle' where everything is connected in harmony and in the 'interpersonal network of life' (Shutte 2001:12; Sindima 1995:127). Sindima (1995:126) conceptualises Ubuntu as a web of life that 'provides a basic framework of the interpretation of the world'. In the 'web of life, there is interdependence and interconnection of ethical relations. The quest for holistic well-being is a common thread that neatly weaves through the existence of humanity. The interdependence and interconnection entail that communities embrace the values of the African worldview of humanness, caring, sharing, respect, compassion and associated values (Broodryk 2002). Pastoral care in a context of Ubuntu is less about therapy but more of an action, where people practically and physically interdepend on each other. This is well conceptualised by one of Lartey's three basic principles of interculturality authentic participation (Lartey 2003:33) that is undertaken 'upon mutual concern for the integrity of the other' (Lartey 2003:33). According to Berinyuu (1988:5) in Africa, 'life is a liturgy of celebration for the victims and/or sacrifices of others'. Everything is interconnected for the well-being of God's creation. Critical to Ubuntu are the ontological and epistemological foundations of caring and well-being. Cornell and Van Marle (2015:3) say the ontological understanding of Ubuntu describes how human beings are 
intertwined and emphasis is on the being of a human. Epistemologically, Cornell and Van Marle (2015) opine:

the being of the human also constitutes how we see the world; for this intertwinement is inherently ethical. When we see...the world, we epistemologically understand it through an inherent ethicality that inheres in our human being with inescapable obligations. (p. 3)

According to Letseka (2012:48), Ubuntu is based on the custom of humanity, which includes caring for each other's well-being and reciprocating kindness. The focus of Ubuntu is the wholeness of human life. Salzberg (2004:8) asserts that 'the quality of kindness gives us the ability to abstract ideals like compassion, or "love thy neighbour", and make them authentic and palpable and vibrant each and every day, going to work or going to school or going home, or getting through a situation we would never in a million years have chosen'. The virtue of caring in Ubuntu is prejudiced by the dignity engraved in humanity influencing my understanding of Ubuntu as a philosophy of pastoral care. Mbiti defines Ubuntu as a philosophy of pastoral care when he says: 'I am, because we are; and since we are, therefore I am' (Mbiti 1969:108-109); in other words, Mbiti says, because I am ontologically connected to other people therefore I am obligated to care for their well-being. The idea of God in creation was for everything to be relational and connected, for everything to depend and interdepended. Thus, Ubuntu is linked to the creation story of the Bible where God immediately assigns human beings, Adam and Eve to extend pastoral care to each other and the rest of creation. Ubuntu is also linked to the historic nature of indigenous African epistemologies, where connectedness and interdependence are the norms of life. According to Ubuntu, philosophy caring cannot be done independently but is a communal role (Letseka 2013a:352). Caregiving is attached to the moral principles of African epistemologies that encourage hospitality, compassion, and respect for human dignity, harmony and generosity (Letseka 2013b:339). Thus, Ubuntu is a principle of pastoral care that has biblical references; from Genesis to Revelations, humanity is constantly reminded of fairness, love, compassion, hospitality, generosity, harmony and sympathy. Ubuntu is also supported by the African worldview and philosophy that is critical to the existence of communities.

Although Ubuntu may have weaknesses (Louw 2010; Ngubane-Mokiwa 2016) like any other philosophy or worldview, it nevertheless guides communities on how moral life is and ought to be. The modern and post-modern conceptualisation of Ubuntu in a context of caregiving is all about the dichotomy of a gendered society. Some existing feminist and gender research on Ubuntu claim that though Ubuntu nurtures the ethic of care, it nevertheless enforces patriarchy and subjugate women to submit to masculine authority (Hall et al. 2013; Mangena 2009:23), whereas others see Ubuntu as a solution to patriarchy (Chitando 2015). I, however, argue that all this is caused by the fluidity and porousness of the concept of Ubuntu where some people abuse it for their personal agendas particularly in enforcing patriarchy, gender binary and social constructions in communities. This has invited some contestations and constantly shifting arguments on what Ubuntu is and is not. I, however, believe that the elderly's perceptions on Ubuntu in a context of caregiving could clear some misunderstandings of this philosophy. It is important to explore how Ubuntu's conceptualisation of caregiving can be used to progressively address and correct these misconceptions. For this to be achieved, pastoral caregiving needs to be conceptualised from African elderly's perspectives of Ubuntu, because they are the custodians of indigenous knowledge (Letseka \& Letseka 2017).

\section{Findings and analysis: Responsiveness}

In this section, I explore KZN elderly people's perceptions of Ubuntu in a context of caregiving. For the elderly from KZN, Ubuntu in a context of caregiving, is marked by responsiveness. According to Mkhulu Bhebhe:

'If it happens that an elderly person's house was destroyed by a storm, and s/he is now too old to build or fix a new home for her or himself ... The community used to meet, all neighbours, women and men were expected to go there and assist their fellow community member...Its similar to when there was death, the person was not supposed to struggle to find out where food will come from, everything came from neighbours ... All neighbours did something to help, if there was death, the King's police went up the mountain and announced that there is death at so and so's family, even if you were doing something you were expected to leave and go there. Everyone was supposed to go there no one remained in their houses all neighbours except for children would go and help with something. It was important to care for each other, we were a community and a one big family, we were related and joined as one community.' (Focus Group Discussions [FGDs] with community elders, 12 February 2015)

The above response by the elderly clearly defines that life was communal and linked. As a result, they used the metaphor of a family to conceptualise how they lived in their communities. In black African contexts, family includes the extended family where there is a broad spectrum of personal associations between families. As a result, Gyekye (1997:292-293) argues that the family is 'the medium for the concrete and spontaneous expression of communal values such as love, caring, cohesion, solidarity, interdependence, mutual sympathy, responsibility and helpfulness'. On the contrary, Letseka (2013a:357) critiques the concept of family as a porous and contested notion that should not be treated as homogenous and unproblematic. Despite some contestations on the family concept, the positive attributes of family that include participation, solidarity, concern for each other, love and interdependence are critical in the foundation of caregiving. Participation for the elderly was essential in the essence of being and humans were always interconnected to one another. Setiloane (1986:14) asserts that a 'human being is not only a vital force, but [she or he] is a vital force in participation'. Participation or sharing of responsibilities was 
influenced, in the African worldview, by the need to depend on each other for survival.

According to the elderly, interdependence or connection of humans was not only visible in times of need and trouble but also during celebrations like weddings and traditional ceremonies. To confirm this gogo Mazeya said:

'A community lived like a family we gathered on weddings and family events. Ceremonies were not attended by invitation, but the whole community was expected to attend and participate the way we did with funerals and grief.' (FGDs with community elders, 12 February 2015)

Both statements confirm that communities lived in an 'unbroken circle' or 'web of life', and the family concept is often used to describe the interconnectedness of the community that is guided by Ubuntu principles. In a 'web of life' or 'unbroken circle', there is no competition, but everything is approached from a communal or extended familial approach. This is consistent with Gelfand (1981:24) who argues that '... the real joy in a person's life comes from giving to or helping others'. Thus, the pastoral caregiving by Christian representatives should be informed by the elderly's views of Ubuntu in a context of caregiving where responsiveness and participation are key. This will encourage pastoral careguvers to respond and participate in different challenges experienced by communities.

There are several themes that emerged from data, which demonstrate that caregiving is not gendered but gender neutral. Themes such as welcoming, hospitality and generosity confirmed that Ubuntu in a context of caregiving was and is not explicitly feminine or gendered.

\section{Welcoming and hospitality}

Ubuntu embraces welcoming travellers, strangers and any visitors; influenced by the Nguni saying isisu somhambi asingani singangenso yenyoni [a traveller's stomach is as small as a bird's kidney]. Travellers among the Zulus were welcomed and given the cooling drink usually amahewu and a place to rest until they were ready to continue their journey. Gogo maThebe said:

'Due to poverty people came from other countries looking for work but they didn't find any work, and the police would harass them about how they got here (in South Africa). So if I came across such a person wherever and had no place to sleep and food, even if I had nothing I would just invite them to come and eat in my house. I would then ask them where they came from? Some would not tell me because they were afraid of their illegal status in South Africa. They would just say "No I left home to work for my wife and kids". Even so I gave them food and prepared a place for them to sleep ... as a result; they multiplied after getting a safe haven in my home. I then started helping them get jobs from people that I knew and that made them refer each other to my place. So to be able to subtract them, my husband helped me in getting them employment to move out.' (FGDs with community elders, 12 February 2015)
The above statement resonates Bishop Verryn's pastoral response towards immigrants and unaccompanied refugee minors (URMS); Verryn opened doors to foreigners as a gesture of welcoming them and emphasised that he was motivated by 'his belief in human agency and respect for human dignity over the human law' (Chisale 2016b:n.p.). Proper care of the traveller or visitor was emphasised by both men and women and they cited respect for human dignity as the motive for their care. The traditional Nguni saying Siyakwamukela or wamlekile ekhaya [you are welcome] showed a traveller that she or he was valued and respected. This care of a traveller was mutually shared between husband and wife because it uplifted their family name. Neighbourliness and participation in extending care and hospitality emerge from the elderly perceptions of Ubuntu in a context of caregiving, and according to participants, this was shared by the husband and the wife. This corresponds with Desmond Tutu's analysis that Ubuntu 'embraces hospitality, caring about others, being willing to go an extra mile for the sake of others ... When I dehumanise you, I inexorably dehumanise myself ...' (Tutu 1999:22). A visitor was an important person among KZN communities. This contradicts the 2015 xenophobic attacks that were supposedly initiated by the Zulu King Goodwill Zwelithini. King Zwelithini contradicted the Ubuntu that Zulus used to practice as they welcomed travellers in their private spaces. However, the gist of gog' umaThebe's statement is that her care for immigrants who found themselves stranded in South Africa was shared with her husband who supported the idea by allowing them to stay in his homestead and helping them get jobs. This suggests that both maThebe and her husband cared. In addition, Mkhulu Zitha said:

\begin{abstract}
'a visitor was supposed to be treated with respect, given proper care until she or he leaves and when she or he leaves we gave him food to eat along the way, cooked meat, mahewu and water for the road. My wife and I felt that because a traveller or a visitor had chosen our home then we were obligated to treat him or her with respect and compassion ... and neighbours would bring more food to help feed the traveller ...' (FGDs with community elders, 12 February 2015)
\end{abstract}

The above findings echo Oyewumi's (2004, 2016) argument that the gendering of men and women in Africa and teaching of biological determinism is foreign in the black African culture. Mkhulu Zitha and gogo maThebe confirm that men and women were equally caring and that they made joint decisions as partners in welcoming travellers in their homesteads.

\section{Generosity}

The African saying izandla ziyagezana [hands wash each other], means that to help each other guided people on how to execute care. It did not matter who extended care as long as care was realised to members of the community and visitors. I asked participants how they addressed poverty and hunger in their communities. Gogo Zibeli said:

'That never happened (poverty and hunger) because kwakunomouniswano [Co-harvesting], izandla ziyagezana, [helping 
each other] let's say we came to a village as a family and built a home and then another family came after us and builds theirs too but they didn't get the chance to sow and weed, so due to Ubuntu we invited them to come and assist us to harvest, when they harvested with us, we then gave them whole lot of maize, butternuts and a lot more that was harvested ... a neighbour who did not have equipment to plough was invited to come and assist so that she or he will be helped plough as well [ukulimisana]. If she or he did not manage to harvest those who had a lot of harvest would invite him or her to help them harvest, so that she or he gets ingqobo [yield/profit], it is said that harvesting comes with ingqobo, so she or he would also get ingqobo of everything that is harvested and had enough to eat with his or her family until the next harvest.' (FGDs with community elders, 12 February 2015)

Poverty was a sign of exclusion from 'the web of life'. If one person lived in poverty, the whole community suffered directly or indirectly because of poverty. As a result, to avoid the suffering of a community, there was generosity and sharing among community members. The ukuvunisana [coharvesting] meant that everyone in a community was expected to live a good and decent life. Co-harvesting and sharing of the yield represent an interpersonal and interdependent community. This suggests that the current poverty some African communities go through is a result of the destruction of the 'web of life'.

\section{Discussion: Implications to pastoral care in an African context}

The subjective responses of participants indicate that Ubuntu in a context of caregiving is not a gendered philosophy. Although the elderly of KZN do not explicitly define Ubuntu as a characteristic of caregiving, their subjective responses confirm that Ubuntu in a context of caregiving is explicitly gender neutral.

\section{Responsiveness in a context of pastoral care}

Themes such as responding to a crisis and responding to a celebration highlighted that both men and women responded in their own rights to a crisis or a celebration. This was motivated by Ubuntu, which required communities to live in 'an unbroken circle'. Feminists argue that the attachment of feelings to responsiveness qualifies this ethic to be feminine; Gilligan (1982) and Noddings (1984) argue that responsiveness is a traditionally female role. Women feel they are obliged to respond because it is their responsibility. African women theologians argue that women swiftly respond to those in need because they believe that they are the anchors of hope (Oduyoye 2001:116). In a context of pastoral care, responsiveness is also feminised. When there is illness, death or any need, PWL is the first to respond. A male pastor and Prayer Men's League (PML) arrives after women have responded. Contrary to this, the elderly of this study highlights that in a context of crisis or celebration, the whole community of men and women responded equally, implying that the gendering of responsiveness in a pastoral care context is erroneous. Perhaps women are the ones who are gendering pastoral care. Women are guilty of internalising oppressive socialisations. African women theologians such as Kamaara and Wangila (2009:131) argue that 'women are not only victims but also perpetrators of oppression against themselves'. Women tend to protect some of the oppressive teachings of culture and tradition. Caregiving is socialised as a feminine role, thus when it comes to issues of caregiving women want to be in the forefront. However, the elderly disputes that caregiving is a feminine role, for the elderly African men and women work together as a community in contexts of caregiving. Ubuntu challenged the whole community to participate in contexts of caregiving irrespective of gender. This challenges pastoral care of the Christian church to reflect on the teachings of Ubuntu.

\section{Welcoming and hospitality in a context of pastoral care}

Welcoming and hospitality are themes that are rarely addressed as pastoral care functions. These themes are very relevant to today's context of migration and xenophobia. According to the elderly, a wife could not welcome a stranger or traveller in a household without the consent of a husband. One of the participants, gogo umaThebe narrated how she took foreigners in her homestead and with the help of her husband assisted them to get jobs. This form of pastoral care was visible in Reverend Paul Verryn's pastoral ministry to migrants in the inner city of Johannesburg. Reverend Verryn welcomed migrants from other countries in the Central Methodist Church in Johannesburg by making the church building a temporary shelter (Chisale 2016b). The elderly's views of Ubuntu in a context of caregiving are parallel to those of Reverend Verryn, that both men and women should partner in extending welcoming and hospitality. Reverend Verryn recruited volunteers from both men and women from the migrant community to participate in extending caregiving to vulnerable migrants, particularly URMs (Chisale 2016b). African women theologians confirm that women believe that they are entitled to caring for the community, including the stranger, as they are anchors of hope (Oduyoye 2001:116). Oduyoye (2001:94) argues that 'hospitality is inherently and genuinely African implying that African values and norms entail every African to be hospitable'. Realistically, hospitality and welcoming are presumed to be feminine. The well-being of a visitor is a responsibility of women who makes sure that a traveller is fed, sleeps in clean linen and baths with warm water. African women theologians argue that such hospitality endangers women by making them vulnerable to rape and other forms of abuse (Oduyoye 2001:104). Thus, the elderly's communal concept or partnership between a husband and wife makes sense as partnership between wife and husband discourages the perpetrators of rape and other forms of abuse on women's bodies. This implies that women and men should work as partners in a context of pastoral care. According to Kasomo (2010):

in traditionally African contexts, fully human undertakings are done conjointly by man and women. The traditional priesthood for instance, embraces both women and men each in his/her own right as a person. (p. 129) 
The implications of this to pastoral care is that one cannot argue that pastoral care is either feminine or masculine because in African contexts this is a partnership between men and women, suggesting that men and women in church should be active pastoral care practitioners.

\section{Generosity in a context of pastoral care}

One of the principles of African women's theology is to establish genuine kindness. According to Njoroge (1996:12), generosity, mutuality, reciprocity and caring are the central principles of community building in Africa. The Ubuntu philosophy in a context of caregiving requires that communities should be generous with each other. Those who have should share with those who do not have. In a context of pastoral care, one cannot just go and be with a person emotionally and psychologically without physically providing for a person. The Christian church is commended for its generosity towards the poor and needy. However, the church is often accused for nurturing the dependence syndrome among the poor and those in need because of the generosity she extends to them. Critiques are mainly those who overlook the reality that Africans are communityoriented people who are compassionate towards one another. Thus, a church planted in Africa should not overlook the significance of generosity among Africans. Msomi (2008:12) rightly argues that Africans should be liberated in a context that is their own and a Christ that is relevant to their context rather than being enslaved in a Christianity that is not their own. For Africans, caregiving is action-oriented where generosity is a communal affair nurtured by the 'web of life' or an 'unbroken circle'. It is significant to note that men and women practically work together in executing generosity. Because in a 'web of life' there is no gender, every person mutually extends kindness and generosity in their own right.

\section{Conclusion}

Ubuntu as conceptualised by the elderly from KZN, can be used to progressively address and correct the gendering of pastoral care in African contexts. The proper order of society is when men and women work in partnership in extending caregiving. Ubuntu in a context of caregiving values communality rather than personality and individualism. As a result, this article argues that pastoral care in an African context should be informed by Ubuntu where the concept of communalism is key. Drawing from oral history conservations on Ubuntu in a context of caregiving with elderly men and women from $K Z N$, findings of this article highlight that caregiving is not gendered, both men and women are custodians of caregiving in their own right and difference. The elderly narrated incidents where men and women demonstrated caregiving in partnership with each other, implying that the gendering of caregiving does not have any basis in the African philosophy. As a result, extending pastoral care should not be a challenge for male clergy in African churches as it is a norm in African communities for men and women to work in partnership. It is significant that in extending pastoral care, the implication of the partnership between men and women should be highlighted and embraced.

\section{Acknowledgements}

This research is part of the National Research Foundation (NRF) funded 'Archaeology of Ubuntu' study, which is a southern African research project that was conducted in Botswana, Lesotho, Namibia, Swaziland, Zambia and Zimbabwe and in the following provinces of South Africa Eastern Cape, KwaZulu-Natal, Limpopo, Mpumalanga and the North West during 2014-2016. Professor Moeketsi Letseka, Department of Educational Foundations, College of Education, University of South Africa, is the project leader.

\section{Competing interests}

The author declares that she has no financial or personal relationships that may have inappropriately influenced her in writing this article.

\section{References}

Babbie, E. \& Mouton, J., 2011, The practice of social research, Oxford University Press, Cape Town.

Berinyuu, A.A., 1988, Pastoral care to the sick in Africa: An approach to transcultura pastoral theology, Peter Lang, Frankfurt, Germany.

Braun, V. \& Clarke, V., 2006, 'Using thematic analysis in psychology', Qualitative ResearchinPsychology3(2),77-101.https://doi.org/10.1191/1478088706qp063oa

Broodryk, J., 2002, Ubuntu: Life lessons from Africa, Ubuntu School of Philosophy, Pretoria.

Chirongoma, S., Manda, D.L. \& Myeni, Z., 2008, ‘Ubuntu and women's health agency in contemporary South Africa', in S. De Gruchy, N. Koopman \& S. Strijbos (eds.), From our side: Emerging perspectives on development and ethics, UNISA Press, From ou
Pretoria.

Chisale, S.S., 2016a, 'Love, discipline, punishment or wife battering: A view from Ubuntu', Gender and Behaviour 14(2), 7277-7285.

Chisale, S.S., 2016b, 'Bishop Paul Verryn's pastoral response towards unaccompanied refugee minors', HTS Teologiese Studies/Theological Studies 72(2), a3411. https:// doi.org/10.4102/hts.v72i2.3411

Chitando, E., 2015, “'Do not tell the person carrying that s/he stinks": Reflections in Ubuntu and masculinities in the context of sexual and gender-based violence and HIV', in E. Mouton, G. Kapuma, L. Hansen \& T. Togom (eds.), Living with dignity: African perspectives on gender equality, Sun Press, Stellenbosch.

Clebsch, W.A. \& Jaeckle, C.R., 1964, Pastoral care in historical perspective, Prentice Hall, Eaglewood Cliffs, NJ.

Cornell, D. \& Van Marle, K., 2015, 'Ubuntu feminism: Tentative reflections', Verbum et Ecclesia 36(2), Art. \#1444, 8 pages. https://doi.org/10.4102/ve.v36i2.1444

Dube, M.W., 2007, 'Feminist theology - Who do you say that I am?', Feminist Theology Journal 15(3), 346-367. https://doi.org/10.1177/0966735006076171

Du Toit, L., 2011, 'Old Wives' tales and philosophical delusions: The problem of women and African Philosophy', in G. Walmsley (ed.), African philosophy and the future of Africa, pp. 111-128, The Council For Research in Values and Philosophy, future of Africa, $\mathrm{pp}$.
Washington, D.C.

Gelfand, M., 1981, Ukama: Reflections on Shona and Western Cultures in Zimbabwe, Mambo Press, Gweru.

Gyekye, K., 1997, Tradition and modernity: Philosophical reflections on the African experience, Oxford University Press, Oxford

Gilligan, C., 1982, In a different voice: Psychological theory and women's development, Harvard University Press, Cambridge, MA.

Hall, D., Du Toit, L. \& Louw, D., 2013, 'Feminist ethics of care and Ubuntu', O and $G$ Forum 23, 29-33.

Held, V., 2005, The ethics of care: Personal, political, and global, Oxford University Press, New York.

Janesick, V.J., 2007, 'Oral history as a social justice project: Issues for the qualitative research', The Qualitative Report 12(1), 111-121.

Jewsiewicki, B. \& Mudimbe, V.Y., 1993, 'Africans' memories and contemporary history of Africa', History and Theory 32(4), 1-11. https://doi.org/10.2307/2505629

Kamaara, E. \& Wangila, M.N., 2009, 'Contextual theology and gender reconstructions in Kenya', Theologies and Cultures VI(2), 110-133.

Kanyoro, M., 2001, Introducing feminist cultural hermeneutics: An African perspective, The Pilgrim Press, Cleveland, $\mathrm{OH}$ 
Kasomo, D., 2010, 'The role of women in the Church in Africa', International Journal of Sociology and Anthropology 2(6), 126-139.

Kasomo, D. \& Maseno, L.M., 2011, 'A critical appraisal of African Feminist Theology', International Journal of Current Research 2(1), 154-162.

Keane, M., 2017, 'Decolonising methodology: Who benefits from indigenous knowledge research?', Educational Research for Social Change 6(1), 12-24. https://doi.org/10.17159/2221-4070/2017/v6i1a2

Lartey, E., 2003, In living color: An intercultural approach to pastoral care and counselling, 2nd edn., Jessica Kingsley Publishers, London and New York.

Letseka, M., 2012, 'In defence of Ubuntu', Studies in Philosophy and Education 31, 47-60. https://doi.org/10.1007/s11217-011-9267-2

Letseka, M., 2013a, 'Anchoring Ubuntu Morality', Mediterranean Journal of Social Sciences 4(3), 351-359. https://doi.org/10.5901/mjss.2013.v4n3p351

Letseka, M., 2013b, 'Educating for Ubuntu/batho: Lessons from Basotho Indigenous Education', Open Journal of Philosophy 3(2), 337-344. https://doi.org/10.4236/ ojpp.2013.32051

Letseka, M. \& Letseka, M.M., 2017, Basotho community elders' views on Botho/ Ubuntu as moral concept, Unpublished.

Louw, D., 2010, 'Power sharing and the challenge of Ubuntu Ethics. Power sharing and African Democracy: Interdisciplinary perspective', in C.W. Dutoit (ed.), Research institute for theology and religion, pp. 121-137, University of South Africa, Pretoria.

Mangena, F., 2009, 'The search for an African feminist ethic: A Zimbabwean perspective', Journal of International Women's Studies 11(2), 18-30.

Manyonganise, M., 2015, 'Oppressive and liberative: A Zimbabwean woman's reflections on Ubuntu', Verbum et Ecclesia 36(2), Art. \#1438, 7 pages. https://doi. org/10.4102/ve.v36i2.1438

Mbiti, J.S., 1969, African religions and philosophy, Doubleday, New York.

Metz, T., 2007, 'Toward an African Moral Theory', The Journal of Political Philosophy 15(3), 321-341. https://doi.org/10.1111/j.1467-9760.2007.00280.x

Mikell, G., 1997, 'Introduction', in G. Mikell (ed.), African feminism: The politics of survival in Sub-Saharan Africa, pp. 1-52, University of Pennsylvania Press, Philadelphia, PA.

Msomi, V.V., 2008, Ubuntu Contextual African Pastoral Care and Counseling: With reflections and dialogues on Zulu Case Studies in a Cross-cultural Perspective, $\mathrm{CB}$ Powell Bible Centre, UNISA, Pretoria.

Ngubane-Mokiwa, S., 2016, 'The challenge of personal and Universal Rights when dealing with pregnancy due to Rape in Rural KwaZulu-Natal', Gender and Behaviour 14(2), 7316-7322.

Nicolaides, A., 2015, 'Gender equity, ethics and feminism: Assumptions of an African Ubuntu Oriented Society', Journal of Social Science 42(3), 191-210. https://doi.or $\mathrm{g} / 10.1080 / 09718923.2015 .11893407$
Njoroge, N., 1996, 'Groaning and languishing in labour pain', in R.A.M. Kanyoro \& J.N. Njoroge (eds.), Groaning in faith: African Women in the household of God, Njoroge (eds.), Groaning in faith:
pp. 3-15, Acton Publishers, Nairobi.

Noddings, N., 1984, Caring: A feminine approach to ethics and moral education, University of California Press, Berkeley, CA.

Noddings, N., 1995, 'Caring: A feminine approach to ethics and moral education', in V. Held (ed.), Rpt. in Justice and Care, pp. 7-30, Westview, Boulder, CO.

Oduyoye, M.A., 2001, Introducing African Women's Theology, Sheffield Academic Press, London.

Oyewumi, O., 2004, 'Conceptualizing gender: The Eurocentric foundations of feminist concepts and the challenge of African Epistemologies', in S. Arnfred, B. Bakare-Yusuf, E.W. Kisiang'ani, D. Lewis, O. Oyewumi \& F.C. Steady (eds.), African gender scholarship. Concepts, methodologies and paradigms, CODESRIA Gender Series, vol. 1, pp. 1-8, Council for the Development of Social Science Research in Africa, Dakar, Senegal.

Oyewumi, O., 2016, What gender is motherhood? Changing Yoru?ba? Ideals of power procreation and identity in the age of modernity, Palgrave Macmillan, New York, NY.

Phiri, I.A., 1997, Women, Presbyterianism and Patriarchy: Religious experiences of Chewa Women in Central Malawi, CLAIM, Blantyre, Malawi.

Rachels, J. \& Rachels, S., 2012, The elements of moral philosophy, 7th edn., McGrawHill International Edition, Singapore.

Salzberg, S., 2004, The force of kindness: Change your life with love and compassion, Sounds True, Boulder, $\mathrm{CO}$.

Setiloane, G., 1986, African theology: An introduction, Skotaville Publishers, Braamfontein.

Shutte, A., 2001, Ubuntu, Cluster Publications, Pietermaritzburg.

Sindima, H.J., 1995, Africa's agenda: The legacy of liberalism and colonialism in the crisis of African values, Westport Connecticut, London.

Sommer, B.W. \& Quinlan, M.K., 2009, The oral history manual, 2nd edn., Altamira Press, New York, NY.

Swedish International Development Cooperation Agency, 2003, Quick guide to what and how: Unpaid care work, entry points to recognise, reduce and redistribute, viewed 10 April 2014, from http://www.sida.se/contentassets/ac479ee77e1f473 e9a7aa1f158a5fa6c/quick-guide-to-what-and-how-unpaid-care-work_3284.pdf

Terre Blanche, M., Durrheim, K. \& Painter, D., 2006, 'Why qualitative research?', in M. Terre Blanche, K. Durrheim \& D. Painter (eds.), Research in practice: Applied methods for the social sciences, pp. 272-284, 2nd edn., UCT Press, Cape Town.

Tutu, D., 1999, No future without forgiveness: A personal overview of South Africa's truth and reconciliation commission, Doubleday Publishers, London.

Vansina, J., 1985, Oral tradition as history, University of Wisconsin Press, Madison, WI.

Wangila, M.N., 2007, Female circumcision: The interplay of religion, culture and gender in Kenya, Orbis Maryknoll, New York, NY. 